\title{
Optimizing the Quality of Life in the Context of Movement Education to Sedentary Students
}

\author{
Elena Moldovan ${ }^{1 *}$, Veronica Mindrescu $^{2}$ \\ ${ }^{1}$ Professor, Department of Motile Performance, University of Transilvania of Brasov, Romania \\ ${ }^{2}$ Lecturer, Department of Motile Performance, University of Transilvania of Brasov, Romania
}

DOI: $10.36348 /$ jaspe.2019.v02i09.002

| Received: 19.11.2019 | Accepted: 26.11.2019 | Published: 28.11.2019

*Corresponding author: Elena Moldovan

Abstract

The present study is the result of a quality study, done by the Transylvania University of Brasov, the target population concerned by the experimentation was composed of 454 students, from this population, a sample of 20 students, (females) they accepted the implementation in their daily activity of a certain individualized kinetic program aiming to optimize the physical condition. The condition was that these activities, along with the kinetic program, be practiced regularly on the duration of the course, to further prove their efficacy in optimizing the physical condition for the people with a sedentary behavior. The subjects involved have presented other associated medical conditions, and they were not selected based on age and sex, these not being considered as selection criteria. The sole selection criterion has been the existence of a sedentary behavior, meaning more than 8 hours per day while sitting down, without doing any ulterior physical activity. The present study analyzes, within 2 evaluations - initial and final - the body's shape and structure (height, weight, thoracic perimeter, amplitude, adapting the organism to effort through the Ruffier test, the cardiac frequency and the adipose tissue.

Keywords: Quality of life, movement, sedentary people.

Copyright @ 2019: This is an open-access article distributed under the terms of the Creative Commons Attribution license which permits unrestricted use, distribution, and reproduction in any medium for non-commercial use (NonCommercial, or CC-BY-NC) provided the original author and source are credited.

\section{INTRODUCTION}

The human body subdued to shaping for constructing a healthy lifestyle represents an architecture which the subject can communicate in his/her own language. Thus, the pedagogical directing in shaping the body as a support for the lifestyle's architecture done though school and social learning is not at all unimportant. In the evolution of a human subject the unity between motile, cognitive, affective and relation is quite conspicuous. The explicative axes of the lifestyle dominated by the motile values are formed by combining 3 basic structures: psychomotricity (with psychological significations), sociomotricity (with collective or social and cultural significations) and etnomotricity (with motile practice significations based on culture, norms, traditions and community rituals of the proximal environment [1]. We highlight the fact that we shall identify as targets of shaping or forming a healthy and elegant way of life the values of education through movement, foreground being some triangular favored couples such as: values perceived or lived, body - motility - knowledge, the human subject having the possibility to acknowledge, assimilate, affirm and know the world and the environment though explorative seeking movement, thus defining the epistemological component of education for the motile development and the motile capacity [2]. Nowadays, on a worldwide level, the sedentary represents the $4^{\text {th }}$ risk factor of mortality $(6 \%$ of demises) and has an increased incidence every day, thus significantly influencing the general health of population and an untransferable prevalence for diseases. In industrialized countries, modernizing the lifestyle goes along with decreasing energetic spending in daily activities and professional activities. If in the past the excessive physical labor facilitated the apparition of the population's premature aging, today, the lifestyle and the modern work conditions, but sedentary ones, stop a lot of people to physical stimulate themselves in maintaining a healthy condition and a good balance [3]. It takes implementing the worldwide recommendations regarding the relation which must exist between the frequency, intensity, duration and type of physical activities necessary for preventing sedentary behavior and other associated diseases [4]. At the base of these diseases is, in most cases, the lack of movement, and the physical exercises can be means through which one can prevent or 
improve many problems of physical or emotional nature. The physical condition or the fitness of a certain person is part of the lifestyle. When the physical condition is at a good level, the daily activities are done successfully, without the presence of an excessive tiredness [5]. Unlike the psychical activity, sedentary behavior is defined as the state in which the movements are reduced to a minimum and the energy spending is close to the energy in repose. Sedentary behavior is not synonym with the absence of activity, but with diverse daily activities that occupy a large part of the day: watching TV, reading, using the computer, driving the car, talking on the phone, etc. Some studies define the sedentary behavior as that behavior in which the activities consume a low level of energy, measured in MET units, meaning less than 1.5 MET (the metabolic equivalent). As an example, one remembers the long periods of relaxation or sitting on a char (mainly 8-10 hours a day). Nevertheless, for other scientists, sedentary behavior represented by the people who do not practice any form of physical activity. Tremblay and his collaborators, highlight the necessity of a uniform definition for describing a sedentary behavior thus suggesting a formula be used, the SITT formula (from English: Sedentary Behavior Frequency, Interruptions, Time, Type) [6]:

1. The sedentary behavior frequency (the number of sessions for a certain period);

2. Interruptions (for example: how many times a person gets up from watching television);

3. Time (the duration of the sedentary behavior);

4. Type (the style of the sedentary behavior or context).

The results of different studies show that time spent doing sedentary activities is, in time, associated with gaining weight. Thus, one has proved that 2 hours more, spent in front of the TV, increase the risk of obesity, after 6 years of TV with $25 \%$. Not only this association has been independent of the regular level of physical activity but also the nutritional input. One believes that the influence of sedentary behaviors on the gaining weight is mediated, at least in part, by associating sedentary behaviors with other customs such as smoking and drinking. The time spent watching $\mathrm{TV}$, during childhood, can influence the later apparition of obesity, especially during adolescence. The studies offer experimental proof of the relation between the time spent watching TV and the increase of the adipose tissue in children [6].

This study has been approached from the perspective of the authors' professions, the physical activities bringing to sedentary people new opportunities with the purpose of acknowledging physical development. Another motif derives from the situation within circle of friends or family, a lot of them not making time for physical activities and the development of movement in order to have a healthy lifestyle. In making this study we have started from the following premises:

- Health is a complex of organic, psychological and social good;

- Man represents a body and soul unity;

- The family history regarding daily customs represents a risk factor which has been a focus for us;

- The physical inactivity, sedentary behavior represents one of the most important primary factors of risk for health and a healthy lifestyle;

This paper has as an objective highlighting education through movement for strenghtening health; increasing the organism's resistance to the pathogen agents from the outer environment; establishing a certain normal psychological and physical balance between the environment and body; presenting the connection between health, physical condition and physical exercise; presenting the roles of certain psychological and biological factors in the systematic practicing of physical exercises. The purpose of these study is to follow the optimization of the quality of life in the students with a sedentary behavior by implementing certain programs of physical education in activating the students that can contribute to this optimization for the sedentary ones. Education for movement has focused on improving the somatic and functional parameters, on adapting the body to effort and on decreasing the adipose tissue.

\section{EXPERIMENTAL SECTION}

A study of 20 of students has been considered with ages between 19-25 years old, from several departments of the Transylvania University of Brasov. The content of the study has been done 3 times a week, the duration of one session being of 30 to 75 minutes, the entire duration of the study being of 3 months. The kinetic programs have been done by alternating the inferior with the superior train, inferior and superior limbs and apparatus exercises. During the 6 months the students have followed a program of physical exercises respecting the principle of longevity in terms of volume, intensity and effort duration. In terms of physical activity as a basic method of education through movement, one has recommended physical exercises in a more slowed down rhythm so that the next step would be a gradual increase of rhythm and the necessity of individualizing the program for each subject.

The kinetic programs have included a short warm up which comprised stretching, exercises for the pectoral muscles and the superior limb muscularity, exercises for the abdomen, sitting down and the inferior limb muscularity, exercises for the waist and hips, exercises with "fitness socks", working on the rolled up carpet and the cycloergometer as well as the Jacobson relaxation. For avoiding monotony and improving 
these programs, the latter have been done on music, the defining element being the rhythm.

The kinetic program for sedentary people has been elaborated for young people in preventing sedentary behavior and its objectives have been:

- Maintaining and increasing the articular suppleness;

- Maintaining and increasing the strength and muscular resistance;

- Maintaining and increasing balance coordination;

- Correcting the body's alignment;

- Maintaining and increasing effort capacity.

The subjects have been encouraged to change their lifestyle by increasing physical activities that they do normally or by introducing the latter in their daily program. Furthermore, the overweight subjects have been encouraged to change their diet by not including a bigger number of aliments in their nutritional way of living.

Each kinetic program has started with a program of stretching exercises of the entire body. The stretching exercises shall respect the following rules:

- One maintains the position for 5-10 seconds;

- A 5-10 seconds pause will be taken before starting a new exercise;

- $\quad$ Each exercise will be repeated 2 times;

- The exercises will have a variable intensity;

- Each session will have a 15 minute time duration;

After finishing the kinetic program one will repeat the stretching exercises.

The stretching exercises of the neck muscularity include:

- Neck extensions and flexing;

- Lateral rotations of the neck;

- Lateral flexion of the neck.

The stretching exercises of the arm, hand, shoulder and back muscularity include:

- Simultaneously lifting and lowering the shoulders exercises;

- Retracting and protecting the shoulders exercises;

- With flexed arms and elbows one will do external and internal rotations of the hands (flexed fingers and slightly apart);

- Flexing and extending the arms;

- One takes the arms to the chest level and with the opposite hand pulls the palm to the level of the elbow to the chest.

The stretching exercises of the trunk and thighs:

- Flexing and extending the spine;
- Lateral inclinations of the spine;

- Rotating the hips;

- Lateral feints;

- Sagittal feints;

- Flexing the trunk by touching with the hands the feet;

- Shaking the superior and inferior limbs.

The program of prophylactic exercises has a duration of 60 minutes, each set of exercises being done in other 3 sets 8 times. These exercises have as major objectives the improvement of the cardio-respiratory apparatus and the corporal composition; these are followed by correcting the posture and the muscular imbalance. The exercises for increasing the muscular mass will focus on the following muscles: the big pectoral, brachial biceps and triceps, the shoulder muscles, spinal extensors, the muscles of the inferior limbs) including also exercises for detensioning tensioned muscles.

The exercises are repetitive, dynamic, including the big groups of muscles, exercises for improving balance, their intensity being moderate.

The exercises included in the program have been elaborated as to be done at home, the subjects being encouraged to do so.

One has turn to the somatic and functional evaluation for determining the main somatic indicators: waist, weight, the body mass index, the waist periphery, the hip periphery, evaluating the mioartrokinetic apparatus through the Hettinger system, evaluating the adaptation to effort to the Ruffier test.

Appreciating the muscular strength of the inferior limbs and the effort capacity through the cardiac apparatus:

- Treadmill running with a constant speed of 8 , appreciating the duration and the distance;

- Elliptic bicycle appreciating the duration and the distance;

- Horizontal bicycle appreciating the duration and the distance.

The data of the individual measurements have been statistically scanned on the computer; depending on the measured indicator, one has calculated the arithmetic average (Xp), the minimum and maximum value, the median and the standard deviation, as well as the variability coefficient, $\mathrm{CV} \%$. Measuring these parameters has been done at the beginning and the end of the study.

\section{RESULTS AND DISCUSSION}

The parameters of the somatic and functional indicators and the evaluation of the organism's adaptation to effort have been the result of the certain evaluation through which more data is collected 
allowing a complex interpretation of the influence of practicing physical education on the general physical development. The obtained results after the initial and final testing have allowed the comparison of the data and identifying the progress rates.

The studied sample comprised 20 subjects with ages between 18 and 25 for whom one has evaluated the physical condition depending on the body mass index and the anthropometric measurements. One has evaluated the distribution of subjects based on age, weight, effort evaluation with the Ruffier test, evaluation of mobility and muscular strength with the help of the Hettinger system.

Table-1: Presenting the date of the initial evaluation

\begin{tabular}{|l|l|l|l|l|l|l|l|}
\hline Nr. & Height & Weight & IMC & Waist periphery & Hip periphery & Hettinger system & Ruffier test \\
\hline $\mathbf{1 .}$ & 170 & 73 & 25.26 & 78 & 113 & 62 & 8 \\
\hline $\mathbf{2 .}$ & 167 & 60 & 21.25 & 73 & 100 & 73 & 8.8 \\
\hline $\mathbf{3 .}$ & 158 & 74 & 29.64 & 78 & 116 & 69 & 5.4 \\
\hline $\mathbf{4 .}$ & 165 & 65 & 23.88 & 64 & 102 & 68 & 11.6 \\
\hline $\mathbf{5 .}$ & 172 & 60 & 20.28 & 74 & 94 & 75 & 7.6 \\
\hline $\mathbf{6 .}$ & 167 & 59 & 21.16 & 72 & 101 & 62 & 4.8 \\
\hline $\mathbf{7 .}$ & 172 & 62 & 20.96 & 70 & 98 & 73 & 7.2 \\
\hline $\mathbf{8 .}$ & 162 & 63 & 23.62 & 76 & 108 & 70 & 9.6 \\
\hline $\mathbf{9 .}$ & 165 & 61 & 23.24 & 73 & 106 & 70 & 6.4 \\
\hline $\mathbf{1 0 .}$ & 165 & 60 & 22.04 & 71 & 96 & 60 & 6 \\
\hline $\mathbf{1 1 .}$ & 167 & 56 & 20.08 & 64 & 98 & 65 & 8 \\
\hline $\mathbf{1 2 .}$ & 155 & 62 & 25.81 & 80 & 101 & 68 & 7.2 \\
\hline $\mathbf{1 3 .}$ & 170 & 67 & 23.18 & 78 & 106 & 66 & 12.8 \\
\hline $\mathbf{1 4 .}$ & 167 & 54 & 19.36 & 70 & 102 & 67 & 8.8 \\
\hline $\mathbf{1 5 .}$ & 168 & 64 & 22.95 & 75 & 100 & 69 & 16.4 \\
\hline $\mathbf{1 6 .}$ & 169 & 57 & 19.96 & 72 & 96 & 61 & 4 \\
\hline $\mathbf{1 7 .}$ & 170 & 54 & 18.32 & 64 & 92 & 74 & 4 \\
\hline $\mathbf{1 8 .}$ & 158 & 53 & 21.23 & 69 & 105 & 64 & 6 \\
\hline $\mathbf{1 9}$. & 166 & 53 & 19.23 & 68 & 96 & 73 & 7.2 \\
\hline $\mathbf{2 0 .}$ & 162 & 80 & 30.48 & 100 & 130 & 57 & 14.4 \\
\hline
\end{tabular}

Table-2: Presenting the data of the final evaluation

\begin{tabular}{|l|l|l|l|l|l|l|l|}
\hline Nr. & Height & Weight & IMC & Waist periphery & Hip periphery & Hettinger system & Ruffier test \\
\hline 1. & 170 & 69 & 23.8 & 76 & 110 & 66 & 7.2 \\
\hline $\mathbf{2 .}$ & 167 & 58 & 20.8 & 70 & 98 & 75 & 8.2 \\
\hline 3. & 158 & 70 & 27.64 & 74 & 114 & 72 & 5 \\
\hline 4. & 165 & 63 & 23.14 & 80 & 100 & 70 & 10 \\
\hline $\mathbf{5 .}$ & 172 & 58 & 19.6 & 73 & 91 & 82 & 6.8 \\
\hline $\mathbf{6 .}$ & 167 & 58 & 20.8 & 70 & 98 & 66 & 4 \\
\hline $\mathbf{7 .}$ & 172 & 63 & 21.3 & 72 & 96 & 78 & 7 \\
\hline $\mathbf{8 .}$ & 162 & 60 & 22.86 & 74 & 106 & 74 & 9 \\
\hline $\mathbf{9 .}$ & 165 & 57 & 20.94 & 70 & 104 & 72 & 6.2 \\
\hline $\mathbf{1 0 .}$ & 165 & 58 & 21.3 & 69 & 95 & 62 & 5 \\
\hline $\mathbf{1 1 .}$ & 167 & 57 & 20.44 & 66 & 100 & 69 & 7.5 \\
\hline $\mathbf{1 2 .}$ & 155 & 60 & 24.97 & 76 & 98 & 71 & 7 \\
\hline $\mathbf{1 3 .}$ & 170 & 65 & 22.49 & 74 & 102 & 69 & 10.2 \\
\hline $\mathbf{1 4 .}$ & 167 & 54 & 19.36 & 70 & 102 & 68 & 8 \\
\hline $\mathbf{1 5 .}$ & 168 & 62 & 22.32 & 73 & 98 & 73 & 12.4 \\
\hline $\mathbf{1 6 .}$ & 169 & 58 & 20.31 & 70 & 94 & 63 & 4 \\
\hline $\mathbf{1 7 .}$ & 170 & 56 & 19.38 & 66 & 94 & 76 & 4 \\
\hline $\mathbf{1 8 .}$ & 158 & 54 & 21.63 & 70 & 100 & 68 & 5.6 \\
\hline $\mathbf{1 9}$. & 166 & 53 & 19.23 & 68 & 96 & 75 & 7 \\
\hline $\mathbf{2 0 .}$ & 162 & 76 & 28.96 & 90 & 120 & 62 & 12.4 \\
\hline
\end{tabular}

The comparative integration and analysis of the research results 
Table-3: The statistic analysis of the study results

\begin{tabular}{|l|l|l|l|l|l|l|l|l|l|l|l|l|l|l|}
\hline & \multicolumn{3}{|l|}{ Weight } & \multicolumn{3}{|l|}{ IMC } & \multicolumn{3}{l|}{$\begin{array}{l}\text { Waist } \\
\text { periphery }\end{array}$} & \multicolumn{2}{l|}{$\begin{array}{l}\text { Hip } \\
\text { periphery }\end{array}$} & \multicolumn{2}{l|}{$\begin{array}{l}\text { Hettinger } \\
\text { system }\end{array}$} & \multicolumn{2}{l|}{ Ruffier test } \\
\cline { 2 - 15 } & Initial & Final & Initial & Final & Initial & Final & Initial & Final & Initial & Final & Initial & Final \\
\hline $\begin{array}{l}\text { Arithmetic } \\
\text { average }\end{array}$ & 61.85 & 60.45 & 22.5 & 22.06 & 73.45 & 72.55 & 103 & 100.8 & 67.3 & 70.55 & 8.21 & 7.32 \\
\hline $\begin{array}{l}\text { Minimal } \\
\text { value }\end{array}$ & 53 & 53 & 18.3 & 19.23 & 64 & 66 & 92 & 91 & 57 & 62 & 4 & 4 \\
\hline $\begin{array}{l}\text { Maximal } \\
\text { value }\end{array}$ & 80 & 76 & 30.48 & 28.96 & 100 & 90 & 130 & 120 & 75 & 82 & 16.4 & 12.4 \\
\hline Median & 60.5 & 58 & 21.6 & 21.3 & 72.5 & 71 & 101 & 99 & 68 & 70.5 & 7.4 & 7 \\
\hline $\begin{array}{l}\text { Standard } \\
\text { deviation }\end{array}$ & 7.25 & 5.87 & 3.24 & 2.63 & 7.85 & 5.37 & 8.80 & 7.142 & 5.11 & 5.33 & 3.34 & 2.51 \\
\hline $\begin{array}{l}\text { Variability } \\
\text { coefficient }\end{array}$ & 5.33 & 4.48 & 2.46 & 1.96 & 5.14 & 3.70 & 6.3 & 5.24 & 4.17 & 4.25 & 2.49 & 1.91 \\
\hline
\end{tabular}

The initial repartition of the subjects depending on the degrees of obesity and the IMC In this study, initially, the Body Mass Index (IMC) has showed values more than 30 , which means $1^{\text {st }}$ degree obesity only in just 1 case $(5 \%)$. Values between 25 and 30 have showed in 4 subjects which stated the presence of overweight in $20 \%$ of the cases. In the majority the IMC has had values between 18,32 and 23,62 indicating a normal body mass present at $75 \%$ of the subjects.

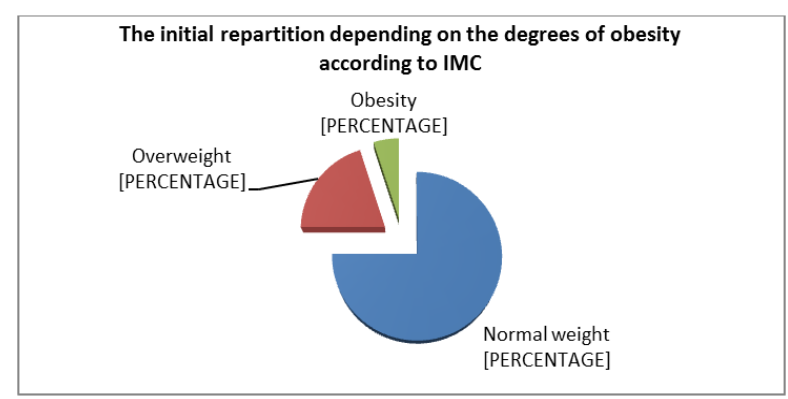

Fig-1: The variation of the subjects depending on IMC

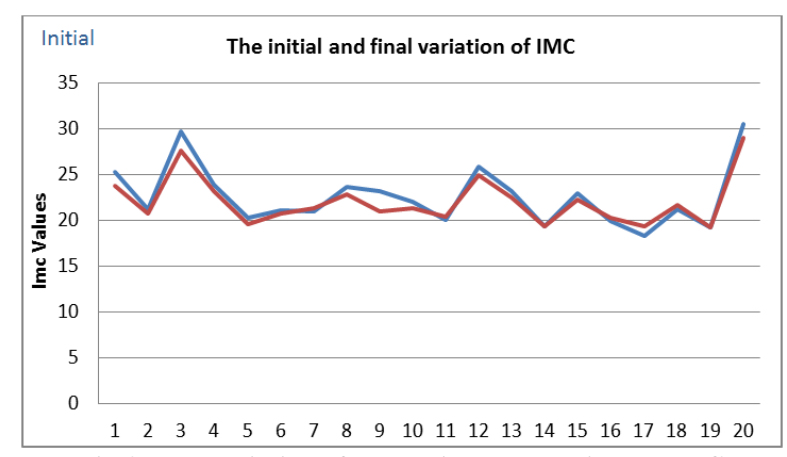

Fig-2: The variation of the subjects depending on IMC

Weight variation

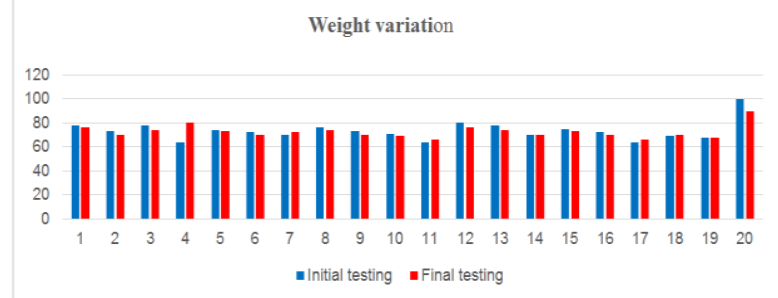

Fig-3: Comparative data of weight
Analyzing the data from Figures 1, 2 and 3 one can notice a considerable decrease in weight to all subjects but also a constant in weight for the nonoverweight subjects with IMC lower than 20. The biggest loss in weight has been presented to subject $\mathrm{x} 20$ with $5 \mathrm{~kg}$ less at the end of the program, going from $1^{\text {st }}$ degree obesity to overweight. Subjects $\mathrm{x} 1, \mathrm{x} 2$, x13, x17 have managed to go from the overweight category to the normal weight category and the subjects with an IMC lower than 19 have managed a growth in weight up to $2 \mathrm{~kg}$ still being in the normal weight category. 3 months after the beginning of the program, the weight evolution has highlighted in all subjects a loss in weight of the body mass with an average of $1,45 \mathrm{~kg}$. If at the beginning of the program the average weight was of $61,85 \mathrm{~kg}$, after 3 months the average was of $60,45 \mathrm{~kg}$.

At the end of the study all subjects have had a alteration of the body mass, one registering an initial value of 22.59 and in the end a value of 22.06. Initially $75 \%$ of the subjects had a body mass between normal and in the end $95 \%$ of them reached normal values.

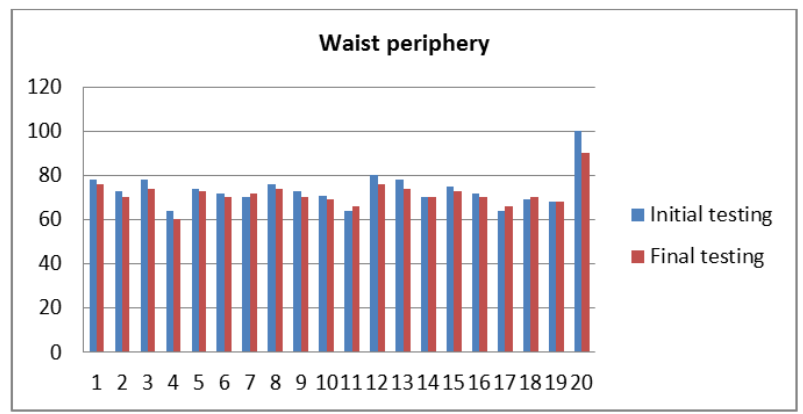

Fig-4: The variation value of the waist periphery

Analyzing the data from Figures-4, the decrease of the medium value of the waist periphery at the end of the program has registered an average of 72.55 in comparison to the initial one of 73.45 . The waist average has been of $2 \mathrm{~cm}$. one has registered maximum decreases of $10 \mathrm{~cm}$ and minimum of 1.2 of the subjects have registered an increase of $2 \mathrm{~cm}$. 
The arithmetic average of the waist periphery

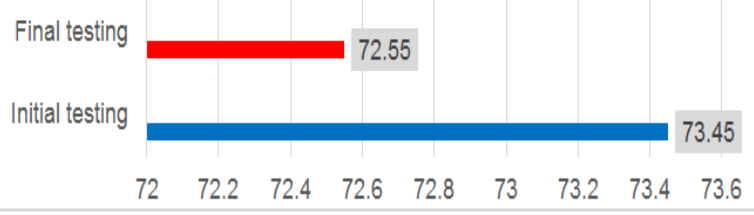

Fig-5: The variation value of the waist periphery

Analyzing the data from Figures-5, before the program the hip periphery had an average of $103 \mathrm{~cm}$, but at the end of the program one has noticed a final value of average $100 \mathrm{~cm}$.

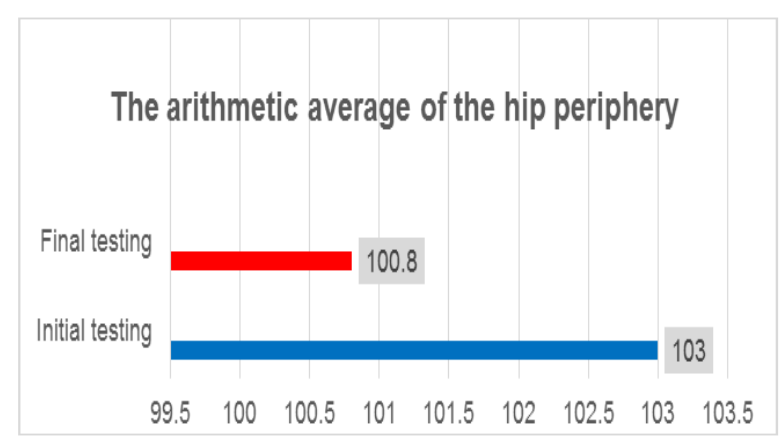

Fig-6: Comparative values of the hip periphery

If previous to the therapy the values showed a majority of $65 \%$ of the subjects with a good score on the appreciation ladder of the test, $30 \%$ medium score and $5 \%$ a low score, at the end of the kinetic prophylaxis program one has showed significant alterations. Depending on the final score after the testing with the help of the Hettinger system, one has noticed a good score in $85 \%$ of the subjects and only $15 \%$ have had a medium score. If the medium initial values were of $67.3 \%$, meaning a medium score, the final ones showed a score of $70.55 \%$, meaning a good score.

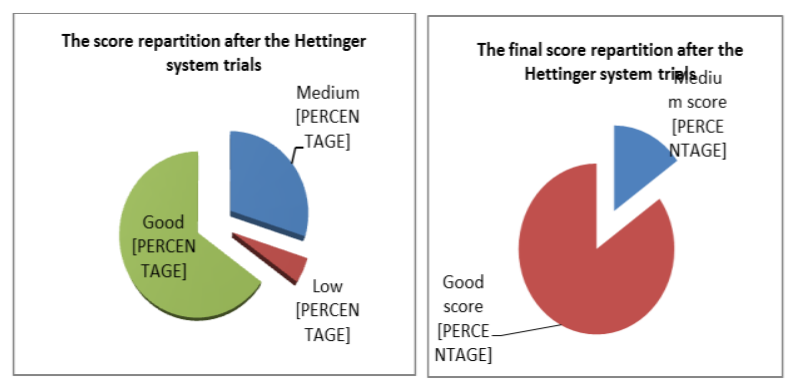

Fig-7: The initial and final score of the Hettinger system

After evaluating the effort capacity, most of the subjects have obtained a satisfying score indicating an acceptable effort capacity; one of the 20 subjects has had an unsatisfying score, 3 a satisfying one, 2 a good score, but none of them managing a very good score. After 16 weeks of program the score has changed considerably, almost all subjects having a lower score on the effort capacity ladder. Thus, the ones obtaining an unsatisfying score have managed to reach a satisfying score, and the majority have reached a medium or good score, thus an increase of the effort capacity.

\begin{tabular}{|c|c|c|c|c|c|c|}
\hline \multicolumn{7}{|c|}{ Table-4: The result } \\
\hline PARAMETER & & $\begin{array}{l}\text { INITIAL } \\
\text { TESTING }\end{array}$ & $\begin{array}{l}\text { FINAL } \\
\text { TESTING }\end{array}$ & $\mathbf{X}$ & $\mathbf{S}$ & Cv\% \\
\hline \multirow[t]{2}{*}{$\begin{array}{l}\text { Treadmill running with a } \\
\text { constant speed of } 8\end{array}$} & Duration & $10 \mathrm{~min}$ & $30 \mathrm{~min}$ & $20 \mathrm{~min}$ & 10,0 & 50,0 \\
\hline & Distance & $1000 \mathrm{~m}$ & $3300 \mathrm{~m}$ & $2150 \mathrm{~m}$ & 115,0 & 53,49 \\
\hline \multirow[t]{2}{*}{ Riding elliptic bicycle } & Duration & $12 \mathrm{~min}$ & $20 \mathrm{~min}$ & $16 \mathrm{~min}$ & 4,0 & 25,0 \\
\hline & Distance & $1000 \mathrm{~m}$ & $1850 \mathrm{~m}$ & $1425 \mathrm{~m}$ & 425,0 & 29,82 \\
\hline \multirow[t]{2}{*}{ Riding horizontal bicycle } & Duration & $20 \min$ & $30 \min$ & $25 \mathrm{~min}$ & 5,0 & 20,0 \\
\hline & Distance & $7250 \mathrm{~m}$ & $11120 \mathrm{~m}$ & $9190 \mathrm{~m}$ & 194 & 21,07 \\
\hline
\end{tabular}

In Table-4 one presents the results of the control trials of the cardio apparatus, regarding treadmill running with a constant speed of 8 ; here, one has appreciated the duration of the initial testing of 10 minutes, running a distance of $1000 \mathrm{~m}$, and to the final testing the duration of 30 minutes on a distance of $3300 \mathrm{~m}$, having a low homogeneity. Riding on an elliptic bicycle, one has appreciated at the initial testing a duration of 12 minutes on a distance of $1000 \mathrm{~m}$, and at the final testing a duration of 20 minutes on a distance of $1850 \mathrm{~m}$, having a low homogeneity. Riding on the horizontal bicycle one has appreciated a duration of 20 minutes on a $7250 \mathrm{~m}$ in the initial testing and for the final one a duration of 30 minutes on a distance of $11120 \mathrm{~m}$, having a moderate homogeneity.

\section{CONCLUSIONS}

Using coherent arguments along with proper calculus, one concludes the following: the hypothesis according to which education through movement has a role in optimizing the quality of life to people with sedentary behavior has been confirmed.

In order to reach the objectives of the paper, we have come up with a kinetic program based on the 
physical activity practiced systematically and accepted by students.

Practicing physical exercises systematically has lead to the improvement of the somatic indicator values as follows:

- We have noticed that after the study, in order to highlight the benefits of movements, for a better quality of life, one has determined the melting of the adipose tissue from the body and not only from a certain region and also the replacement with muscular tissue;

- Losing weight and adipose tissue has lead to obtaining an "elegant" posture with positive effects on the physical state and the psychological one;

Through a sustained and rhythmic program of physical exercises one has improved the physical condition of the students through the organism's better adaptation to effort.

The proposed kinetic program has also improved the articular mobility which has as a first result the diminishing of the risk of accidents, health problems and the apparition of different physical deficiencies.

Regarding the results of the control trials to the cardiac apparatus, one highlights a significant increase of the exercises difficulty and the variation of the number of repetitions, the difference of the progress rate depending on the construction of the apparatus, the group, and muscular area requested.

To what the control trials are concerned, to the cardiac apparatus one notices an increase of the work duration on each apparatus and the distances, in the same time depending on the order of the usage from the beginning to the end of the training and depending on the apparatus (treadmill, elliptic bicycle, horizontal bicycle). Education through movement ensures the premises of the biometric development of the students and focuses generally on the healthy custom of practicing physical exercises with the final purpose of improving the quality of life.

\section{REFERENCES}

1. Mano, R. (2012). Nuove visioni dell'allenamento delle capacita di resistenza a fini preventivi; ruolo dell' aumento delle intensita, l'esempio della HIT (High Intensiti Interval Training), e altri esempi. Cinesiologia scientifica.

2. Hahn B. D., \& Payne, A. W. (1997). Focus on health, Edition III, WCB McGraw, Boston.

3. Aquatias, S. (2008). Activité physique- Contextes et effets sur la santé, Inserm, Paris.

4. Bauman, A., Lewicka, M., \& Schöppe, S. (2005). The health benefits of physical activity in developing countries. Organisation Mondial de la Sante, Geneve, 24.

5. Bauwens, M. (2011). Evaluation d'un programme de lutte contre la sédentarité au sein du Réseau Sport Santé Bien-Etre de Champagne-Ardenne. Nancy-Université, Université Henri Poincaré, 9,10 .

6. Tremblay, M. S., Aubert, S., Barnes, J. D., Saunders, T. J., Carson, V., Latimer-Cheung, A. E., ... \& Chinapaw, M. J. (2017). Sedentary behavior research network (SBRN)-terminology consensus project process and outcome. International Journal of Behavioral Nutrition and Physical Activity, 14(1), 75. 